\title{
Fixed point theorems for generalized weakly contractive mappings in metric spaces with applications
}

\section{Seonghoon Cho*}

"Correspondence:

shcho@hanseo.ac.kr

Department of Mathematics,

Hanseo University, Seosan, South Korea

\begin{abstract}
In this paper, motivated and inspired by Samet et al., we introduce the notion of generalized weakly contractive mappings in metric spaces and prove the existence and uniqueness of fixed point for such mappings, and we obtain a coupled fixed point theorem in metric spaces. These theorems generalize many previously obtained fixed point results. An example is given to illustrate the main result. Finally, we give applications of our results to fixed point results in partial metric spaces.
\end{abstract}

MSC: $47 \mathrm{H} 10 ; 54 \mathrm{H} 25$

Keywords: fixed point; coupled fixed point; generalized weak contractive mapping

\section{Introduction and preliminaries}

In 1977, Alber et al. [1] generalized Banach's contraction principle by introducing the concept of weak contraction mappings in Hilbert spaces. Weak contraction principle states that every weak contraction mapping on a complete Hilbert space has a unique fixed point. Rhoades [2] extended weak contraction principle in Hilbert spaces to metric spaces. Since then, many authors (for example, [3-14]) obtained generalizations and extensions of the weak contraction principle. Khan et al. [15] obtained fixed point theorems in metric spaces by introducing the concept of altering distance functions.

In particular, Choudhury et al. [8] obtained a generalization of the weak contraction principle in metric spaces by using altering distance functions as follows.

Theorem 1.1 ([8]) Suppose that a mapping $g: X \rightarrow X$, where $X$ is a metric space with metric $d$, satisfies the following condition:

$$
\begin{aligned}
& \psi(d(g x, g y)) \\
& \leq \psi\left(\max \left\{d(x, y), d(x, g x), d(y, g y), \frac{1}{2}\{d(x, g y)+d(y, g x)\}\right\}\right) \\
& \quad-\phi(\max \{d(x, y), d(y, g y)\})
\end{aligned}
$$

(c) The Author(s) 2018. This article is distributed under the terms of the Creative Commons Attribution 4.0 International License (http://creativecommons.org/licenses/by/4.0/), which permits unrestricted use, distribution, and reproduction in any medium, provided you give appropriate credit to the original author(s) and the source, provide a link to the Creative Commons license, and indicate if changes were made. 
for all $x, y \in X$, where $\phi:[0, \infty) \rightarrow[0, \infty)$ is a continuous function, and $\psi:[0, \infty) \rightarrow[0, \infty)$ is an altering distance function, that is, $\psi$ is a nondecreasing and continuous function, and $\psi(t)=0$ if and only if $t=0$.

Then $T$ has a unique fixed point.

Matthews [16] introduced the notion of partial metric spaces, and extended Banach's contraction principle to partial metric spaces, and then a lot of authors gave fixed point results in partial metric spaces (see [5, 17-30]). Also, Aydi et al. [31] extended Ekeland's variational principle to partial metric spaces, and Aydi et al. [32] extended Caristi's fixed point theorem to partial metric spaces.

In particular, Abdeljawad [3] extended the result of Choudhury et al. [8] to partial metric spaces.

Samet et al. [33] gave a generalization of Banach's contraction principle and an application to fixed point results in partial metric spaces.

In this paper, motivated and inspired by Samet et al. [33], we introduce the notion of generalized weakly contractive mappings in metric spaces and prove a fixed point theorem for generalized weakly contractive mappings defined on complete metric spaces, which is a generalization of the results of $[8-10,33]$. Also, we obtain a coupled fixed point theorem in metric spaces by applying our main result, and we give applications to fixed point and coupled fixed point theorems in partial metric spaces.

A function $f: X \rightarrow[0, \infty)$, where $X$ is a metric space, is called lower semicontinuous if, for all $x \in X$ and $\left\{x_{n}\right\} \subset X$ with $\lim _{n \rightarrow \infty} x_{n}=x$, we have

$$
f(x) \leq \lim _{n \rightarrow \infty} \inf f\left(x_{n}\right)
$$

Let

$$
\Psi=\{\psi:[0, \infty) \rightarrow[0, \infty) \mid \psi \text { is continuous and } \psi(t)=0 \Leftrightarrow t=0\}
$$

Also, we denote

$$
\Phi=\{\phi:[0, \infty) \rightarrow[0, \infty) \mid \phi \text { is lower semicontinuous and } \phi(t)=0 \Leftrightarrow t=0\} .
$$

Lemma 1.1 ([34]) If a sequence $\left\{x_{n}\right\}$ in $X$ is not Cauchy, then there exist $\epsilon>0$ and two subsequences $\left\{x_{m(k)}\right\}$ and $\left\{x_{n(k)}\right\}$ of $\left\{x_{n}\right\}$ such that $m(k)$ is the smallest index for which $m(k)>$ $n(k)>k$,

$$
d\left(x_{m(k)}, x_{n(k)}\right) \geq \epsilon,
$$

and

$$
d\left(x_{m(k)-1}, x_{n(k)}\right)<\epsilon .
$$

Moreover, suppose that $\lim _{n \rightarrow \infty} d\left(x_{n}, x_{n+1}\right)=0$.

Then we have:

(1) $\lim _{n \rightarrow \infty} d\left(x_{m(k)}, x_{n(k)}\right)=\epsilon$; 
(2) $\lim _{n \rightarrow \infty} d\left(x_{m(k)-1}, x_{n(k)-1}\right)=\epsilon$;

(3) $\lim _{n \rightarrow \infty} d\left(x_{m(k)}, x_{n(k)-1}\right)=\epsilon$;

(4) $\lim _{n \rightarrow \infty} d\left(x_{m(k)-1}, x_{n(k)}\right)=\epsilon$.

\section{Fixed point results}

Let $X$ be a metric space with metric $d$, let $T: X \rightarrow X$, and let $\varphi: X \rightarrow[0, \infty)$ be a lower semicontinuous function.

Then $T$ is called a generalized weakly contractive mapping if it satisfies the following condition:

$$
\begin{aligned}
& \psi(d(T x, T y)+\varphi(T x)+\varphi(T y)) \\
& \quad \leq \psi(m(x, y, d, T, \varphi))-\phi(l(x, y, d, T, \varphi)) \quad \forall x, y \in X
\end{aligned}
$$

where $\psi \in \Psi, \phi \in \Phi$, and

$$
\begin{aligned}
m(x, y, d, T, \varphi)= & \max \{d(x, y)+\varphi(x)+\varphi(y), d(x, T x)+\varphi(x)+\varphi(T x), \\
& d(y, T y)+\varphi(y)+\varphi(T y), \frac{1}{2}\{d(x, T y)+\varphi(x)+\varphi(T y) \\
& +d(y, T x)+\varphi(y)+\varphi(T x)\}\}
\end{aligned}
$$

and

$$
l(x, y, d, T, \varphi)=\max \{d(x, y)+\varphi(x)+\varphi(y), d(y, T y)+\varphi(y)+\varphi(T y)\} .
$$

Let $X$ be a metric space with metric $d$, let $T: X \rightarrow X$, and let $\varphi: X \rightarrow[0, \infty)$ be a lower semicontinuous function.

Theorem 2.1 Let $X$ be complete. If $T$ is a generalized weakly contractive mapping, then there exists a unique $z \in X$ such that $z=T z$ and $\varphi(z)=0$.

Proof Let $x_{0} \in X$ be a fixed point, and define a sequence $\left\{x_{n}\right\}$ by $x_{n+1}=T x_{n}$ for all $n=$ $0,1,2, \ldots$.

If $x_{n}=x_{n+1}$ for some $n$, then $x_{n}=x_{n+1}=T x_{n}$. So $x_{n}$ is a fixed point of $T$, and the proof is finished.

From now on, assume that $x_{n} \neq x_{n+1}$ for all $n=0,1,2, \ldots$

From (2.2) with $x=x_{n-1}$ and $y=x_{n}$ we have

$$
\begin{aligned}
m\left(x_{n-1}, x_{n}, d, T, \varphi\right) & =\max \left\{d\left(x_{n-1}, x_{n}\right)+\varphi\left(x_{n-1}\right)+\varphi\left(x_{n}\right),\right. \\
& d\left(x_{n-1}, T x_{n-1}\right)+\varphi\left(x_{n-1}\right)+\varphi\left(T x_{n-1}\right), d\left(x_{n}, T x_{n}\right)+\varphi\left(x_{n}\right)+\varphi\left(T x_{n}\right), \\
& \left.\frac{1}{2}\left\{d\left(x_{n-1}, T x_{n}\right)+\varphi\left(x_{n-1}\right)+\varphi\left(T x_{n}\right)+d\left(x_{n}, T x_{n-1}\right)+\varphi\left(x_{n}\right)+\varphi\left(T x_{n-1}\right)\right\}\right\} .
\end{aligned}
$$


Since

$$
\begin{aligned}
& \frac{1}{2}\left\{d\left(x_{n-1}, T x_{n}\right)+\varphi\left(x_{n-1}\right)+\varphi\left(T x_{n}\right)+d\left(x_{n}, T x_{n-1}\right)+\varphi\left(x_{n}\right)+\varphi\left(T x_{n-1}\right)\right\} \\
& \quad=\frac{1}{2}\left\{d\left(x_{n-1}, x_{n+1}\right)+\varphi\left(x_{n-1}\right)+\varphi\left(x_{n+1}\right)+d\left(x_{n}, x_{n}\right)+\varphi\left(x_{n}\right)+\varphi\left(x_{n}\right)\right\} \\
& \quad \leq \frac{1}{2}\left\{d\left(x_{n-1}, x_{n}\right)+\varphi\left(x_{n-1}\right)+\varphi\left(x_{n}\right)+d\left(x_{n}, x_{n+1}\right)+\varphi\left(x_{n}\right)+\varphi\left(x_{n+1}\right)\right\} \\
& \leq \max \left\{d\left(x_{n-1}, x_{n}\right)+\varphi\left(x_{n-1}\right)+\varphi\left(x_{n}\right), d\left(x_{n}, x_{n+1}\right)+\varphi\left(x_{n}\right)+\varphi\left(x_{n+1}\right)\right\}
\end{aligned}
$$

we obtain

$$
\begin{aligned}
& m\left(x_{n-1}, x_{n}, d, T, \varphi\right) \\
& \quad=\max \left\{d\left(x_{n-1}, x_{n}\right)+\varphi\left(x_{n-1}\right)+\varphi\left(x_{n}\right), d\left(x_{n}, x_{n+1}\right)+\varphi\left(x_{n}\right)+\varphi\left(x_{n+1}\right)\right\} .
\end{aligned}
$$

Also, we have

$$
\begin{aligned}
& l\left(x_{n-1}, x_{n}, d, T, \varphi\right) \\
& \quad=\max \left\{d\left(x_{n-1}, x_{n}\right)+\varphi\left(x_{n-1}\right)+\varphi\left(x_{n}\right), d\left(x_{n}, T x_{n}\right)+\varphi\left(x_{n}\right)+\varphi\left(T x_{n}\right)\right\} \\
& \quad=\max \left\{d\left(x_{n-1}, x_{n}\right)+\varphi\left(x_{n-1}\right)+\varphi\left(x_{n}\right), d\left(x_{n}, x_{n+1}\right)+\varphi\left(x_{n}\right)+\varphi\left(x_{n+1}\right)\right\} .
\end{aligned}
$$

It follows from (2.1) that

$$
\begin{aligned}
& \psi\left(d\left(x_{n}, x_{n+1}\right)+\varphi\left(x_{n}\right)+\varphi\left(x_{n+1}\right)\right) \\
& \quad=\psi\left(d\left(T x_{n-1}, T x_{n}\right)+\varphi\left(T x_{n-1}\right)+\varphi\left(T x_{n}\right)\right) \\
& \quad \leq \psi\left(m\left(x_{n-1}, x_{n}, d, T, \varphi\right)\right)-\phi\left(l\left(x_{n-1}, x_{n}, d, T, \varphi\right)\right) .
\end{aligned}
$$

If

$$
d\left(x_{n-1}, x_{n}\right)+\varphi\left(x_{n-1}\right)+\varphi\left(x_{n}\right)<d\left(x_{n}, x_{n+1}\right)+\varphi\left(x_{n}\right)+\varphi\left(x_{n+1}\right)
$$

for some positive integer $n$, then from (2.5) we obtain

$$
\begin{aligned}
& \psi\left(d\left(x_{n}, x_{n+1}\right)+\varphi\left(x_{n}\right)+\varphi\left(x_{n+1}\right)\right) \\
& \quad \leq \psi\left(d\left(x_{n}, x_{n+1}\right)+\varphi\left(x_{n}\right)+\varphi\left(x_{n+1}\right)\right)-\phi\left(d\left(x_{n}, x_{n+1}\right)+\varphi\left(x_{n}\right)+\varphi\left(x_{n+1}\right)\right),
\end{aligned}
$$

which implies

$$
\phi\left(d\left(x_{n+1}, x_{n}\right)+\varphi\left(x_{n+1}\right)+\varphi\left(x_{n}\right)\right)=0,
$$

and so

$$
d\left(x_{n+1}, x_{n}\right)+\varphi\left(x_{n+1}\right)+\varphi\left(x_{n}\right)=0 .
$$


Hence

$$
x_{n+1}=x_{n} \quad \text { and } \quad \varphi\left(x_{n+1}\right)=\varphi\left(x_{n}\right)=0 \text {, }
$$

which is a contradiction.

Thus we have

$$
d\left(x_{n}, x_{n+1}\right)+\varphi\left(x_{n}\right)+\varphi\left(x_{n+1}\right) \leq d\left(x_{n-1}, x_{n}\right)+\varphi\left(x_{n-1}\right)+\varphi\left(x_{n}\right)
$$

for all $n=1,2,3, \ldots$, and so

$$
m\left(x_{n-1}, x_{n}, d, T, \varphi\right)=d\left(x_{n-1}, x_{n}\right)+\varphi\left(x_{n-1}\right)+\varphi\left(x_{n}\right)
$$

and

$$
l\left(x_{n-1}, x_{n}, d, T, \varphi\right)=d\left(x_{n-1}, x_{n}\right)+\varphi\left(x_{n-1}\right)+\varphi\left(x_{n}\right)
$$

for all $n=1,2,3, \ldots$.

It follows from $(2.5)$ that

$$
\begin{aligned}
& \psi\left(d\left(x_{n}, x_{n+1}\right)+\varphi\left(x_{n}\right)+\varphi\left(x_{n+1}\right)\right) \\
& \leq \psi\left(d\left(x_{n-1}, x_{n}\right)+\varphi\left(x_{n-1}\right)+\varphi\left(x_{n}\right)\right) \\
& \quad-\phi\left(d\left(x_{n-1}, x_{n}\right)+\varphi\left(x_{n-1}\right)+\varphi\left(x_{n}\right)\right) .
\end{aligned}
$$

It follows from (2.6) that the sequence $\left\{d\left(x_{n}, x_{n+1}\right)+\varphi\left(x_{n}\right)+\varphi\left(x_{n+1}\right)\right\}$ is nonincreasing. Thus we have

$$
d\left(x_{n}, x_{n+1}\right)+\varphi\left(x_{n}\right)+\varphi\left(x_{n+1}\right) \rightarrow r \quad \text { as } n \rightarrow \infty
$$

for some $r \geq 0$.

Assume that $r>0$.

Letting $n \rightarrow \infty$ in (2.7), by the continuity of $\psi$ and the lower semicontinuity of $\phi$ it follows that

$$
\begin{aligned}
\psi(r) & \leq \psi(r)-\lim _{n \rightarrow \infty} \inf \phi\left(d\left(x_{n-1}, x_{n}\right)+\varphi\left(x_{n-1}\right)+\varphi\left(x_{n}\right)\right) \\
& \leq \psi(r)-\phi(r) .
\end{aligned}
$$

Since $r>0, \phi(r)>0$. Hence

$$
\psi(r) \leq \psi(r)-\phi(r)<\psi(r)
$$

a contradiction.

Hence

$$
\lim _{n \rightarrow \infty}\left\{d\left(x_{n}, x_{n+1}\right)+\varphi\left(x_{n}\right)+\varphi\left(x_{n+1}\right)\right\}=0,
$$


which implies

$$
\lim _{n \rightarrow \infty} d\left(x_{n}, x_{n+1}\right)=0
$$

and

$$
\lim _{n \rightarrow \infty} \varphi\left(x_{n}\right)=0
$$

Now, we prove that the sequence $\left\{x_{n}\right\}$ is Cauchy.

If $\left\{x_{n}\right\}$ is not Cauchy, then by Lemma 1.1 there exist $\epsilon>0$ and subsequences $\left\{x_{m(k)}\right\}$ and $\left\{x_{n(k)}\right\}$ of $\left\{x_{n}\right\}$ such that (1.2) and (1.3) hold.

From (2.2) we have

$$
\begin{aligned}
m\left(x_{n(k)}, x_{m(k)}, d, T, \varphi\right) & \\
= & \max \left\{d\left(x_{n(k)}, x_{m(k)}\right)+\varphi\left(x_{n(k)}\right)+\varphi\left(x_{m(k)}\right),\right. \\
& d\left(x_{n(k)}, T x_{n(k)}\right)+\varphi\left(x_{n(k)}\right)+\varphi\left(T x_{n(k)}\right), d\left(x_{m(k)}, T x_{m(k)}\right)+\varphi\left(x_{m(k)}\right)+\varphi\left(T x_{m(k)}\right), \\
& \left.\frac{1}{2}\left\{d\left(x_{n(k)}, T x_{m(k)}\right)+\varphi\left(x_{n(k)}\right)+\varphi\left(T x_{m(k)}\right)+d\left(x_{m(k)}, T x_{n(k)}\right)+\varphi\left(x_{m(k)}\right)+\varphi\left(T x_{n(k)}\right)\right\}\right\} \\
= & \max \left\{d\left(x_{n(k)}, x_{m(k)}\right)+\varphi\left(x_{n(k)}\right)+\varphi\left(x_{m(k)}\right), d\left(x_{n(k)}, x_{n(k)+1}\right)+\varphi\left(x_{n(k)}\right)+\varphi\left(x_{n(k)+1}\right),\right. \\
& d\left(x_{m(k)}, x_{m(k)+1}\right)+\varphi\left(x_{m(k)}\right)+\varphi\left(x_{m(k)+1}\right), \frac{1}{2}\left\{d\left(x_{n(k)}, x_{m(k)+1}\right)+\varphi\left(x_{n(k)}\right)+\varphi\left(x_{m(k)+1}\right)\right. \\
& \left.\left.+d\left(x_{m(k)}, x_{n(k)+1}\right)+\varphi\left(x_{m(k)}\right)+\varphi\left(x_{n(k)+1}\right)\right\}\right\} .
\end{aligned}
$$

Letting $k \rightarrow \infty$ in (2.10) and applying Lemma 1.1, (2.8), and (2.9), it follows that

$$
\lim _{k \rightarrow \infty} m\left(x_{n(k)}, x_{m(k)}, d, T, \varphi\right)=\epsilon
$$

Also, it follows from (2.3) that

$$
\begin{aligned}
& l\left(x_{n(k)}, x_{m(k)}, d, T, \varphi\right) \\
& \quad=\max \left\{d\left(x_{n(k)}, x_{m(k)}\right)+\varphi\left(x_{n(k)}\right)+\varphi\left(x_{m(k)}\right), d\left(x_{m(k)}, T x_{m(k)}\right)+\varphi\left(x_{m(k)}\right)+\varphi\left(T x_{m(k)}\right)\right\} \\
& \quad=\max \left\{d\left(x_{n(k)}, x_{m(k)}\right)+\varphi\left(x_{n(k)}\right)+\varphi\left(x_{m(k)}\right), d\left(x_{m(k)}, x_{m(k)+1}\right)+\varphi\left(x_{m(k)}\right)+\varphi\left(x_{m(k)+1}\right)\right\} .
\end{aligned}
$$

Hence

$$
\lim _{n \rightarrow \infty} l\left(x_{n(k)}, x_{m(k)}, d, T, \varphi\right)=\epsilon .
$$

From (2.1) we have

$$
\begin{aligned}
& \psi\left(d\left(x_{n(k)+1}, x_{m(k)+1}\right)+\varphi\left(x_{n(k)+1}\right)+\varphi\left(x_{m(k)+1}\right)\right) \\
& \quad \leq \psi\left(m\left(x_{n(k)}, x_{m(k)}, d, T, \varphi\right)\right)-\phi\left(l\left(x_{n(k)}, x_{m(k)}, d, T, \varphi\right)\right) .
\end{aligned}
$$


Letting $k \rightarrow \infty$ in this inequality, by Lemma 1.1 , the continuity of $\psi$, the lower semicontinuity of $\phi$, and by (2.9), (2.11), and (2.12) we have

$$
\psi(\epsilon) \leq \psi(\epsilon)-\phi(\epsilon)
$$

which is a contradiction because $\phi(\epsilon)>0$.

Hence the sequence $\left\{x_{n}\right\}$ is Cauchy, and hence

$$
\lim _{n \rightarrow \infty} x_{n}=z \in X \text { exists }
$$

because $X$ is complete. Since $\varphi$ is lower semicontinuous,

$$
\varphi(z) \leq \lim _{n \rightarrow \infty} \inf \varphi\left(x_{n}\right) \leq \lim _{n \rightarrow \infty} \varphi\left(x_{n}\right)=0,
$$

which implies

$$
\varphi(z)=0 .
$$

It follows from (2.2) that

$$
\begin{aligned}
m\left(x_{n}, z, d, T, \varphi\right)= & \max \left\{d\left(x_{n}, z\right)+\varphi\left(x_{n}\right)+\varphi(z),\right. \\
& d\left(x_{n}, T x_{n}\right)+\varphi\left(x_{n}\right)+\varphi\left(T x_{n}\right), d(z, T z)+\varphi(z)+\varphi(T z), \\
& \left.\frac{1}{2}\left\{d\left(x_{n}, T z\right)+\varphi\left(x_{n}\right)+\varphi(T z)+d\left(z, T x_{n}\right)+\varphi(z)+\varphi\left(T x_{n}\right)\right\}\right\} \\
= & \max \left\{d\left(x_{n}, z\right)+\varphi\left(x_{n}\right)+\varphi(z),\right. \\
& d\left(x_{n}, x_{n+1}\right)+\varphi\left(x_{n}\right)+\varphi\left(x_{n+1}\right), d(z, T z)+\varphi(z)+\varphi(T z), \\
& \left.\frac{1}{2}\left\{d\left(x_{n}, T z\right)+\varphi\left(x_{n}\right)+\varphi(T z)+d\left(z, x_{n+1}\right)+\varphi(z)+\varphi\left(x_{n+1}\right)\right\}\right\} .
\end{aligned}
$$

So we have

$$
\lim _{n \rightarrow \infty} m\left(x_{n}, z, d, T, \varphi\right)=d(z, T z)+\varphi(z)+\varphi(T z)=d(z, T z)+\varphi(T z) .
$$

Also, we have

$$
\begin{aligned}
\lim _{n \rightarrow \infty} l\left(x_{n}, z, d, T, \varphi\right) & =\lim _{n \rightarrow \infty} \max \left\{d\left(x_{n}, z\right)+\varphi\left(x_{n}\right)+\varphi(z), d(z, T z)+\varphi(z)+\varphi(T z)\right\} \\
& =d(z, T z)+\varphi(z)+\varphi(T z)=d(z, T z)+\varphi(T z) .
\end{aligned}
$$

It follows from (2.1) that

$$
\begin{aligned}
\psi\left(d\left(x_{n+1}, T z\right)+\varphi\left(x_{n+1}\right)+\varphi(T z)\right) & =\psi\left(d\left(T x_{n}, T z\right)+\varphi\left(T x_{n}\right)+\varphi(T z)\right) \\
& \leq \psi\left(m\left(x_{n}, z, d, T, \varphi\right)\right)-\phi\left(l\left(x_{n}, z, d, T, \varphi\right)\right) .
\end{aligned}
$$


By taking the limit as $n \rightarrow \infty$ in (2.16) and by applying the continuity of $\psi$, the lower semicontinuity of $\phi,(2.14)$, and (2.15) we have

$$
\psi(d(z, T z)+\varphi(T z)) \leq \psi(d(z, T z)+\varphi(T z))-\phi(d(z, T z)+\varphi(T z)) .
$$

Hence $d(z, T z)+\varphi(T z)=0$, and hence $z=T z$ and $\varphi(T z)=0$.

Suppose that $u$ is another fixed point of $T$.

Then

$$
u=T u \quad \text { and } \quad \varphi(u)=0 .
$$

By applying (2.1) with $x=z$ and $y=u$ we have

$$
\begin{aligned}
\psi(d(z, u)) & =\psi(d(T z, T u)) \\
& =\psi(d(T z, T u)+\varphi(T z)+\varphi(T u)) \\
& \leq \psi(m(z, u, d, T, \varphi))-\phi(l(z, u, d, T, \varphi)) \\
& =\psi(d(z, u))-\phi(d(z, u))
\end{aligned}
$$

which implies $z=u$.

The following example illustrates Theorem 2.1 and shows that it is a real generalization of Theorem 3.1 in [8].

Example 2.1 Let $X=[0, \infty)$ and $d(x, y)=|x-y|$ for $x, y \in X$, let $\psi(t)=\frac{3}{2} t$ for $t \geq 0$, and let

$$
\varphi(t)= \begin{cases}\frac{1}{2} t & (0 \leq t \leq 1) \\ \frac{1}{2} t+\frac{1}{2} & (1<t \leq 2) \\ t & (t>2)\end{cases}
$$

Then $\psi \in \Psi, \varphi$ is lower semicontinuous, and $\frac{1}{2} t \leq \varphi(t) \leq t, t \geq 0$.

Define the map $T: X \rightarrow X$ by

$$
T x=\frac{x^{2}}{2(1+x)} .
$$

Assume that a function $\phi:[0, \infty) \rightarrow[0, \infty)$ is defined by

$$
\phi(t)=\frac{3 t}{4+2 t} .
$$

Then $\phi \in \Phi$.

We now show that (2.1) holds.

Without loss of generality, suppose that $x \geq y$. 
Then we have

$$
\begin{aligned}
\frac{1}{2}\{d(x, T y)+\varphi(x)+\varphi(T y)+d(y, T x)+\varphi(y)+\varphi(T x)\} \\
\quad \geq \frac{1}{2}\left\{d(x, T y)+\frac{1}{2} x+\frac{1}{2} T y+d(y, T x)+\frac{1}{2} y+\frac{1}{2} T x\right\} \\
\geq \frac{1}{2}\left\{\frac{1}{2}\{d(x, T y)+x+T y+d(y, T x)+y+T x\}\right\} \\
\quad= \begin{cases}\frac{1}{2}\left\{x+\frac{x^{2}}{1+x}\right\} & \left(y \leq \frac{x^{2}}{2(1+x)}\right), \\
\frac{1}{2}\{x+y\} & \text { otherwise }\end{cases} \\
>\frac{1}{2} x .
\end{aligned}
$$

Thus we have

$$
\begin{aligned}
m(x, y, d, T, \varphi) & \\
= & \max \{d(x, y)+\varphi(x)+\varphi(y), d(x, T x)+\varphi(x)+\varphi(T x), \\
& \left.d(y, T y)+\varphi(y)+\varphi(T y), \frac{1}{2}\{d(x, T y)+\varphi(x)+\varphi(T y)+d(y, T x)+\varphi(y)+\varphi(T x)\}\right\} \\
\geq & \frac{1}{2} \max \{d(x, y)+x+y, d(x, T x)+x+T x, \\
& \left.d(y, T y)+y+T y, \frac{1}{2}\{d(x, T y)+x+T y+d(y, T x)+y+T x\}\right\} \\
= & \frac{1}{2} \max \left\{2 x, 2 x, 2 y, \frac{1}{2} x\right\} \\
= & x
\end{aligned}
$$

and

$$
\begin{aligned}
l(x, y, d, T, \varphi) & =\max \{d(x, y)+\varphi(x)+\varphi(y), d(y, T y)+\varphi(y)+\varphi(T y)\} \\
& \leq \max \{d(x, y)+x+y, d(y, T y)+y+T y\} \\
& =\max \{2 x, 2 y\} \\
& =2 x .
\end{aligned}
$$

Also, we have

$$
\begin{aligned}
\psi(d(T x, T y)+\varphi(T x)+\varphi(T y)) & \leq \psi(d(T x, T y)+T x+T y) \\
& =\frac{3}{2}\left(\left|\frac{x^{2}}{2(1+x)}-\frac{y^{2}}{2(1+y)}\right|+\frac{x^{2}}{2(1+x)}+\frac{y^{2}}{2(1+y)}\right) \\
& =\frac{3}{2} \cdot \frac{2 x^{2}}{2(1+x)} \\
& =\frac{3}{2} \cdot \frac{x^{2}}{1+x} .
\end{aligned}
$$


Hence

$$
\begin{aligned}
\psi(m(x, y, d, T, \varphi))-\phi(l(x, y, d, T, \varphi)) & \geq \frac{3}{2} x-\frac{3 x / 2}{1+x} \\
& =\frac{3}{2} \cdot \frac{x^{2}}{1+x} \\
& \geq \psi(d(T x, T y)+\varphi(T x)+\varphi(T y)),
\end{aligned}
$$

where the equality is satisfied when $x=0$.

Thus (2.1) is satisfied.

By Theorem 2.1, $T$ has a unique fixed point $z=0$, and $\varphi(z)=0$.

However, (1.1) is not satisfied. In fact, let $x=3, y=1$, and $\varphi(t)=0, t \geq 0$.

Then

$$
\begin{aligned}
& \psi(m((x, y, d, T, \varphi)))=\frac{45}{2}, \\
& \phi(l((x, y, d, T, \varphi)))=\frac{3}{4}, \\
& \psi(d(T x, T y))=\frac{51}{2},
\end{aligned}
$$

and so

$$
\psi(d(T x, T y))=\frac{204}{8}>\frac{147}{8}=\psi(m((x, y, d, T, \varphi)))-\phi(l((x, y, d, T, \varphi))) .
$$

The proofs of the following Corollary 2.2 and Corollary 2.3 are similar to that of Theorem 2.1. So, here the proofs are omitted.

Corollary 2.2 Let $X$ be complete. Suppose that $T$ satisfies the following condition:

$$
\begin{gathered}
\psi(d(T x, T y)+\varphi(T x)+\varphi(T y)) \\
\leq \psi(m(x, y, d, T, \varphi))-\phi(m(x, y, d, T, \varphi)) \\
\forall x, y \in X, \text { where } \psi \in \Psi \text { and } \phi \in \Phi .
\end{gathered}
$$

Then there exists a unique $z \in X$ such that $z=T z$ and $\varphi(z)=0$.

Corollary 2.3 Let $(X, d)$ be complete. Suppose that $T$ satisfies the following condition:

$$
\begin{aligned}
& \psi(d(T x, T y)+\varphi(T x)+\varphi(T y)) \\
& \leq \psi(d(x, y)+\varphi(x)+\varphi(y))-\phi(d(x, y)+\varphi(x)+\varphi(y)) \\
& \quad \forall x, y \in X, \text { where } \psi \in \Psi \text { and } \phi \in \Phi .
\end{aligned}
$$

Then there exists a unique $z \in X$ such that $z=T z$ and $\varphi(z)=0$. 
Corollary 2.4 Let $X$ be complete. Suppose that $T$ satisfies the following condition:

$$
\begin{aligned}
& \psi\left(d\left(T^{k} x, T^{k} y\right)+\varphi\left(T^{k} x\right)+\varphi\left(T^{k} y\right)\right) \\
& \quad \leq \psi\left(m\left(x, y, d, T^{k}, \varphi\right)\right)-\phi\left(l\left(x, y, d, T^{k}, \varphi\right)\right) \\
& \quad \forall x, y \in X, \text { where } \psi \in \Psi, \phi \in \Phi, \text { and } k \text { is a positive integer. }
\end{aligned}
$$

Then there exists a unique $z \in X$ such that $z=T z$ and $\varphi(z)=0$.

Proof Let $S=T^{k}$. Then by Theorem $2.1 S$ has a unique fixed point, say $z$.

Then $T^{k} z=S z=z$ and

$$
\varphi(z)=\varphi(S z)=\varphi\left(T^{k} z\right)=0 .
$$

Since $T^{k+1} z=T z$,

$$
S T z=T^{k}(T z)=T^{k+1} z=T z
$$

and so $T z$ is a fixed point of $S$. By the uniqueness of a fixed point of $S, T z=z$.

Remark 2.1 If we have $\varphi=0$, then $\psi$ is nondecreasing and continuous, and $\phi$ is continuous in Theorem 2.1 (resp. Corollary 2.3, Corollary 2.4), then we obtain Theorem 3.1 of [8] (resp. Theorem 2.1 of [10], Corollary 3.1 of [8]).

Remark 2.2 If $\varphi=0$ and if $\psi$ and $\phi$ are nondecreasing and continuous in Corollary 2.3, then we obtain Theorem 2.1 of [10].

Remark 2.3 If $\varphi=0$ and $\psi$ is nondecreasing and continuous in Corollary 2.2, then we obtain Theorem 2.2 of [9].

\section{Discussion}

In this section, we obtain a new coupled fixed point result from Theorem 2.1.

Let $X$ be a nonempty set.

We say that $(x, y) \in X \times X$ is a coupled fixed point [35] of a mapping $G: X \times X \rightarrow X$ if

$$
G(x, y)=x \quad \text { and } \quad G(y, x)=y .
$$

Lemma 3.1 ([36]) Let $X$ be a nonempty set, $(x, y) \in X \times X$, and let $G: X \times X \rightarrow X$.

Then the following are equivalent.

(1) $G(x, y)=x$ and $G(y, x)=y$;

(2) $H(x, y)=(x, y)$, that is, $H$ has a fixed point $(x, y)$, where $H: X \times X \rightarrow X \times X$ is a mapping defined by

$$
H(x, y)=(G(x, y), G(y, x))
$$

Lemma 3.2 ([37]) Let $(X, d)$ be a complete metric space (resp. complete partial metric space). 
Define $\rho: X \times X \rightarrow[0, \infty)$ by

$$
\rho((x, y),(u, v))=\max \{d(x, u), d(y, v)\} .
$$

Then $(X \times X, \rho)$ is a complete metric space (resp. complete partial metric space).

Let $(X, d)$ be a metric space (or partial metric space), $G: X \times X \rightarrow X$, and let $H:(X \times$ $X, \rho) \rightarrow(X \times X, \rho)$ be a mapping defined as in (3.1).

Let

$$
\begin{aligned}
M( & \left.(x, y),(u, v), d, G, \varphi^{*}\right) \\
= & \max \left\{\max \{d(x, u), d(y, v)\}+\varphi^{*}(x, y)+\varphi^{*}(u, v),\right. \\
& \max \{d(x, G(x, y)), d(y, G(y, x))\}+\varphi^{*}(x, y)+\varphi^{*}(G(x, y), G(y, x)), \\
& \max \{d(u, G(u, v)), d(v, G(v, u))\}+\varphi^{*}(u, v)+\varphi^{*}(G(u, v), G(v, u)), \\
& \frac{1}{2}\left[\operatorname { m a x } \left\{d(x, G(u, v)), d(y, G(v, u))+\varphi^{*}(x, y)+\varphi^{*}(G(u, v), G(v, u))\right.\right. \\
& \left.\left.+\max \{d(u, G(x, y)), d(v, G(y, x))\}+\varphi^{*}(u, v)+\varphi^{*}(G(x, y), G(y, x))\right]\right\},
\end{aligned}
$$

and let

$$
\begin{aligned}
L\left((x, y),(u, v), d, G, \varphi^{*}\right) \\
\quad=\max \left\{\max \{d(x, u), d(y, v)\}+\varphi^{*}(x, y)+\varphi^{*}(u, v),\right. \\
\left.\quad \max \{d(u, G(x, y)), d(v, G(y, x))\}+\varphi^{*}(u, v)+\varphi^{*}(G(x, y), G(y, x))\right\},
\end{aligned}
$$

where $\varphi^{*}: X \times X \rightarrow[0, \infty)$.

Then we have

$$
\begin{aligned}
& M\left((x, y),(u, v), d, G, \varphi^{*}\right) \\
&= \max \left\{\rho((x, y),(u, v))+\varphi^{*}(x, y)+\varphi^{*}(u, v),\right. \\
& \rho((x, y), H(x, y))+\varphi^{*}(x, y)+\varphi^{*}(H(x, y)), \\
& \rho((u, v), H(u, v))+\varphi^{*}(u, v)+\varphi^{*}(H(u, v)), \\
& \frac{1}{2}\left[\rho((x, y), H(u, v))+\varphi^{*}(x, y)+\varphi^{*}(H(u, v))\right. \\
&\left.\left.+\rho((u, v), H(x, y))+\varphi^{*}(u, v)+\varphi^{*}(H(x, y))\right]\right\} \\
&= m\left((x, y),(u, v), \rho, H, \varphi^{*}\right) .
\end{aligned}
$$

Also, we have

$$
L\left((x, y),(u, v), d, G, \varphi^{*}\right)=l\left((x, y),(u, v), \rho, H, \varphi^{*}\right) .
$$


Theorem 3.1 Let $X$ be complete. Suppose that $G: X \times X \rightarrow X$ is a mapping such that

$$
\begin{gathered}
\psi(d(G(x, y), G(u, v))+\varphi(G(x, y), G(y, x))+\varphi(G(u, v), G(v, u))) \\
\leq \psi\left(M\left((x, y),(u, v), d, G, \varphi^{*}\right)\right)-\phi\left(L\left((x, y),(u, v), d, G, \varphi^{*}\right)\right)
\end{gathered}
$$

for all $(x, y),(u, v) \in X \times X$, where $\psi \in \Psi, \phi \in \Phi$, and $\varphi^{*}: X \times X \rightarrow[0, \infty)$ is lower semicontinuous.

Then $G$ has a unique coupled fixed point $\left(x^{*}, y^{*}\right) \in X \times X$, and $\varphi^{*}\left(x^{*}, y^{*}\right)=0$.

Proof Let $\rho$ be the metric on $X \times X$ defined as (3.2), and let $H:(X \times X, \rho) \rightarrow(X \times X, \rho)$ be a mapping defined as in (3.1) for $(x, y),(u, v) \in X \times X$.

It follows from (3.3), (3.4), and (3.5) that

$$
\rho(H(x, y), H(u, v)) \leq \psi\left(m\left((x, y),(u, v), \rho, H, \varphi^{*}\right)-\phi\left(l\left((x, y),(u, v), \rho, H, \varphi^{*}\right)\right)\right.
$$

for $(x, y),(u, v) \in X \times X$.

By Theorem 2.1, $H$ has a unique fixed point, and so by Lemma $3.1 \mathrm{G}$ has a unique coupled fixed point.

Corollary 3.2 Let $X$ be complete. Suppose that $G: X \times X \rightarrow X$ is a mapping such that

$$
\begin{array}{r}
\psi(d(G(x, y), G(u, v))+\varphi(G(x, y), G(y, x))+\varphi(G(u, v), G(v, u))) \\
\leq \psi\left(M\left((x, y),(u, v), d, G, \varphi^{*}\right)\right)-\phi\left(M\left((x, y),(u, v), d, G, \varphi^{*}\right)\right)
\end{array}
$$

for all $(x, y),(u, v) \in X \times X$, where $\psi \in \Psi, \phi \in \Phi$, and $\varphi^{*}: X \times X \rightarrow[0, \infty)$ is lower semicontinuous.

Then $G$ has a unique coupled fixed point $\left(x^{*}, y^{*}\right) \in X \times X$, and $\varphi^{*}\left(x^{*}, y^{*}\right)=0$.

Corollary 3.3 Let $X$ be complete. Suppose that $G: X \times X \rightarrow X$ is a mapping such that

$$
\begin{gathered}
\psi(d(G(x, y), G(u, v))+\varphi(G(x, y), G(y, x))+\varphi(G(u, v), G(v, u))) \\
\leq \psi\left(\max \{d(x, u), d(y, v)\}+\varphi^{*}(x, y)+\varphi^{*}(u, v)\right) \\
-\phi\left(\max \{d(x, u), d(y, v)\}+\varphi^{*}(x, y)+\varphi^{*}(u, v)\right)
\end{gathered}
$$

for all $(x, y),(u, v) \in X \times X$, where $\psi \in \Psi, \phi \in \Phi$, and $\varphi^{*}: X \times X \rightarrow[0, \infty)$ is lower semicontinuous.

Then $G$ has a unique coupled fixed point $\left(x^{*}, y^{*}\right) \in X \times X$, and $\varphi^{*}\left(x^{*}, y^{*}\right)=0$.

Taking $\varphi^{*}=0$ in Theorem 3.1, we have the following corollary.

Corollary 3.4 Let $X$ be complete. Suppose that $G: X \times X \rightarrow X$ is a mapping such that

$$
\psi(d(G(x, y), G(u, v))) \leq \psi(M((x, y),(u, v), d, G, 0)-\phi(L((x, y),(u, v), d, G, 0))
$$

for all $(x, y),(u, v) \in X \times X$, where $\psi \in \Psi$ and $\phi \in \Phi$.

Then $G$ has a unique coupled fixed point. 
Corollary 3.5 Let $X$ be complete. Suppose that $G: X \times X \rightarrow X$ is a mapping such that

$$
\begin{aligned}
& \psi(d(G(x, y), G(u, v))) \\
& \quad \leq \psi(M((x, y),(u, v), d, G, 0)-\phi(M((x, y),(u, v), d, G, 0))
\end{aligned}
$$

for all $(x, y),(u, v) \in X \times X$, where $\psi \in \Psi$ and $\phi \in \Phi$.

Then $G$ has a unique coupled fixed point.

Corollary 3.6 Let $X$ be complete. Suppose that $G: X \times X \rightarrow X$ is a mapping such that

$$
\begin{aligned}
& \psi(d(G(x, y), G(u, v))) \\
& \quad \leq \psi(\max \{d(x, u), d(y, v)\}-\phi(\max \{d(x, u), d(y, v)\})
\end{aligned}
$$

for all $(x, y),(u, v) \in X \times X$, where $\psi \in \Psi$ and $\phi \in \Phi$.

Then $G$ has a unique coupled fixed point.

\section{Applications}

In this section, we give application to fixed point theorems in partial metric spaces.

Recall some definitions and basic results in partial metric spaces. For more details, we refer to [16].

Let $Z$ be a nonempty set. A function $p: Z \times Z \rightarrow[0, \infty)$ is called a partial metric on $Z$ if, for all $x, y, z \in Z$, the following are satisfied:

(1) $p(x, x)=p(y, y)=p(x, y) \Leftrightarrow x=y$;

(2) $p(x, x) \leq p(x, y)$;

(3) $p(x, y)=p(y, x)$;

(4) $p(x, z) \leq p(x, y)+p(y, z)-p(y, y)$.

The pair $(Z, p)$ is called a partial metric space.

Note that if $p(x, y)=0$, then $x=y$.

An example of a partial metric defined on $[0, \infty)$ is $p(x, y)=\max \{x, y\}, x, y \geq 0$. For more examples of partial metrics, we refer to [16].

It is well known that each partial metric $p$ on a nonempty set $Z$ generates a $T_{0}$ topology on $Z$ and that $\{B(x, \epsilon): \epsilon>0, x \in Z\}$ is a base for the topology, where $B(x, \epsilon)=\{y \in Z$ : $p(x, y)<p(x, x)+\epsilon\}$ for all $x \in Z$ and $\epsilon>0$.

Also, it is known that the function $p_{s}: Z \times Z \rightarrow[0, \infty)$ defined by

$$
p_{s}(x, y)=2 p(x, y)-p(x, x)-p(y, y)
$$

is a metric on $Z$.

Let $Z$ be a partial metric space with partial metric $p$, let $\left\{x_{n}\right\}(\subset Z)$ be a sequence, and let $x \in Z$. Then we say that

(1) $\left\{x_{n}\right\}$ is convergent to $x$ if $\lim _{n \rightarrow \infty} p\left(x, x_{n}\right)=p(x, x)$;

(2) $\left\{x_{n}\right\}$ is called a Cauchy sequence if there exists $\lim _{n, m \rightarrow \infty} p\left(x_{n}, x_{m}\right)$ such that it is finite;

(3) $Z$ is complete if every Cauchy sequence in $Z$ is convergent to a point $z \in Z$ such that

$$
\lim _{n, m \rightarrow \infty} p\left(x_{n}, x_{m}\right)=p(z, z)
$$


Remark 4.1 A partial metric space $Z$ is complete if and only if for every Cauchy sequence $\left\{x_{n}\right\}$ in $Z$, there exists $z \in Z$ such that

$$
\lim _{n, m \rightarrow \infty} p\left(x_{n}, x_{m}\right)=\lim _{n, m \rightarrow \infty} p\left(x_{n}, z\right)=p(z, z) .
$$

Remark 4.2 Let $\left\{x_{n}\right\}(\subset Z)$ be a sequence, and let $x \in Z$. If the sequence $\left\{x_{n}\right\}$ is convergent to $x$ in $\left(Z, p_{s}\right)$, then it is convergent to $x$ in $(Z, p)$, and the converse is not true (see [16]).

\subsection{Fixed points on partial metric spaces}

Theorem 4.1 Let $Z$ be complete with partial metric $p$. Suppose that $T: Z \rightarrow Z$ is a mapping such that

$$
\begin{aligned}
\psi(p(T x, T y)) \leq & \psi\left(\max \left\{p(x, y), p(x, T x), p(y, T y), \frac{1}{2}\{p(x, T y)+p(y, T x)\}\right\}\right) \\
& -\phi(\max \{p(x, y), p(y, T y)\})
\end{aligned}
$$

for all $x, y \in Z$, where $\psi \in \Psi$ and $\phi \in \Phi$.

Then there exists a unique $z \in Z$ such that $z=T z$ and $p(z, z)=0$.

Proof From (4.1) we have

$$
p(x, y)=\frac{p_{s}(x, y)+p(x, x)+p(y, y)}{2}
$$

for all $x, y \in Z$.

Let $d(x, y)=\frac{p_{s}(x, y)}{2}$ and $\varphi(x)=\frac{p(x, x)}{2}$ for all $x, y \in Z$.

Then $Z$ is a complete metric space with metric $d$, and $\varphi: Z \rightarrow[0, \infty)$ is a lower semicontinuous function. Also, (4.2) reduces to (2.1). By Theorem 2.1 there exists a unique $z \in Z$ such that $z=T z$ and $p(z, z)=0$.

Remark 4.3 Theorem 4.1 is a generalization of Theorem 8 of [3]. In fact, let $\phi$ and $\psi$ be nondecreasing and continuous functions.

Then Theorem 4.1 reduces to Theorem 8 of [3].

Corollary 4.2 Let $Z$ be complete with partial metric $p$. Suppose that $T: Z \rightarrow Z$ is a mapping such that

$$
\begin{aligned}
\psi(p(T x, T y)) \leq & \psi\left(\max \left\{p(x, y), p(x, T x), p(y, T y), \frac{1}{2}\{p(x, T y)+p(y, T x)\}\right\}\right) \\
& -\phi\left(\max \left\{p(x, y), p(x, T x), p(y, T y), \frac{1}{2}\{p(x, T y)+p(y, T x)\}\right\}\right)
\end{aligned}
$$

for all $x, y \in Z$, where $\psi \in \Psi$ and $\phi \in \Phi$.

Then there exists a unique $z \in Z$ such that $z=T z$ and $p(z, z)=0$.

Remark 4.4 If $\phi$ is continuous in Corollary 4.2, then we obtain Theorem 2.5 of [6]. 
Corollary 4.3 Let $Z$ be complete with partial metric $p$. Suppose that $T: Z \rightarrow Z$ is a mapping such that

$$
\psi(p(T x, T y)) \leq \psi(p(x, y))-\phi(p(x, y))
$$

for all $x, y \in Z$, where $\psi \in \Psi$ and $\phi \in \Phi$.

Then there exists a unique $z \in Z$ such that $z=T z$ and $p(z, z)=0$.

\subsection{Coupled fixed points on partial metric spaces}

Theorem 4.4 Let $Z$ be complete with partial metric $p$. Suppose that $G: Z \times Z \rightarrow Z$ is a mapping such that

$$
\begin{aligned}
& \psi(p(G(x, y), G(u, v))) \\
& \quad \leq \psi(M((x, y),(u, v), p, G, 0))-\phi(L((x, y),(u, v), p, G, 0))
\end{aligned}
$$

for all $(x, y),(u, v) \in Z \times Z$, where $\psi \in \Psi$ and $\phi \in \Phi$.

Then $G$ has a unique coupled fixed point.

Proof Let $\rho$ be the partial metric on $Z \times Z$ defined as in (3.2), and let $H:(Z \times Z, \rho) \rightarrow$ $(Z \times Z, \rho)$ be a mapping defined as in (3.1).

It follows from (4.3), (3.3), and (3.4) with $\varphi^{*}=0$ that

$$
\rho(H(x, y), H(u, v)) \leq \psi(m((x, y),(u, v), \rho, H, 0)-\phi(l((x, y),(u, v), \rho, H, 0))
$$

for all $(x, y),(u, v) \in Z \times Z$.

By Theorem 4.1, $H$ has a unique fixed point, and so by Lemma $3.1 \mathrm{G}$ has a unique coupled fixed point.

Corollary 4.5 Let $Z$ be complete with partial metric $p$. Suppose that $G: Z \times Z \rightarrow Z$ is a mapping such that

$$
\begin{aligned}
& \psi(p(G(x, y), G(u, v))) \\
& \quad \leq \psi(M((x, y),(u, v), p, G, 0))-\phi(M((x, y),(u, v), p, G, 0))
\end{aligned}
$$

for all $(x, y),(u, v) \in Z \times Z$, where $\psi \in \Psi$ and $\phi \in \Phi$.

Then $G$ has a unique coupled fixed point.

Corollary 4.6 Let $Z$ be complete with partial metric $p$. Suppose that $G: Z \times Z \rightarrow Z$ is a mapping such that

$$
\begin{aligned}
& \psi(p(G(x, y), G(u, v))) \\
& \quad \leq \psi(\max \{p(x, y), p(u, v)\})-\phi(\max \{p(x, y), p(u, v)\})
\end{aligned}
$$

for all $(x, y),(u, v) \in Z \times Z$, where $\psi \in \Psi$ and $\phi \in \Phi$.

Then $G$ has a unique coupled fixed point. 


\title{
5 Conclusions
}

Motivated by the result of Samet et al. [33], we introduce the notion of generalized weakly contractive mappings and prove the existence and uniqueness of fixed points for such mappings. We give applications to the existence of fixed points in partial metric spaces.

This investigation can be extended to a quasi-metric spaces with applications to studies of fixed points in quasi-partial metric spaces.

\author{
Acknowledgements \\ The author would like to thank the anonymous reviewers and editor for their valuable comments. \\ Funding \\ "Not applicable" \\ Abbreviations \\ "Not applicable" \\ Availability of data and materials \\ "Not applicable" \\ Competing interests \\ The author declares that he has no competing interests.
}

Authors' contributions

The author read and approved the final manuscript.

\section{Publisher's Note}

Springer Nature remains neutral with regard to jurisdictional claims in published maps and institutional affiliations.

Received: 15 October 2017 Accepted: 9 January 2018 Published online: 05 February 2018

\section{References}

1. Alber, Yal, Guerre-Delabriere, S: Principles of weakly contractive maps in Hilbert spaces. In: Goldberg, I, Lyubich, Yu (eds.) New Results in Operator Theory. Advances and Appl., vol. 98, pp. 7-12. Birkhäuser, Basel (1977) Topology and its Applications 157, 2778-2785 (2010)

2. Rhoades, BE: Some theorems on weakly contractive maps. Nonlinear Anal. 47, 2683-2693 (2001)

3. Abdeljawad, T: Fixed points for generalized weakly contractive mappings in partial metric spaces. Math. Comput. Model. 54, 2923-2927 (2011)

4. Aydi, H: On common fixed point theorems for $(\psi, \varphi)$-generalized $f$-weakly contractive mappings. Miskolc Math. Notes 14, 19-30 (2013)

5. Aydi, H, Karapinar, E, Shatanawi, W: Coupled fixed point results for $(\psi, \varphi)$-weakly contractive condition in ordered partial metric spaces. Comput. Math. Appl. 62, 4449-4460 (2011)

6. Chi, KP, Karapinar, E, Thanh, TD: On the fixed point theorems for generalized weakly contractive mappings on partial metric spaces. Bull. Iran. Math. Soc. 30, 369-381 (2013)

7. Cho, SH: Fixed point theorems for weakly $\alpha$-contractive mappings with application. Appl. Math. Sci. 7, 2953-2965 (2013)

8. Choudhury, BS, Konar, P, Rhoades, BE, Metiya, N: Fixed point theorems for generalized weakly contractive mappings. Nonlinear Anal. 74, 2116-2126 (2011)

9. Doric, D: Common fixed point for generalized $(\psi, \varphi)$-weak contractions. Appl. Math. Lett. 22, 1896-1900 (2009)

10. Dutta, PN, Choudhury, BS: A generalization of contraction principle in metric spaces. Fixed Point Theory Appl. 2008, Article ID 406368 (2008)

11. Isik, H, Turkoglu, D: Fixed point theorems for weakly contractive mappings in partially ordered metric-like spaces. Fixed Point Theory Appl. 2013, 51 (2013)

12. Lakzian, $\mathrm{H}$, Samet, B: Fixed points for $(\psi, \varphi)$-weakly contractive mappings in generalized metric spaces. Appl. Math. Lett. 25, 902-906 (2012)

13. Moradi, S, Farajzadeh, A: On fixed point of $(\psi-\varphi)$-weak and generalized $(\psi-\varphi)$-weak contraction mappings. Appl. Math. Lett. 25, 1257-1262 (2012)

14. Popescu, O: Fixed points for $(\psi-\phi)$-weak contractions. Appl. Math. Lett. 24, 1-4 (2011)

15. Khan, MS, Swaleh, M, Sessa, S: Fixed point theorems by altering distances between the points. Bull. Aust. Math. Soc. 30, 1-9 (1984)

16. Matthews, SG: Partial metric topology. Ann. N.Y. Acad. Sci. 78, 183-197 (1994)

17. Abdeljawad, T, Aydi, H, Karapinar, E: Coupled fixed points for Meir-Keeler contractions in ordered partial metric spaces. Math. Probl. Eng. 2012, Article ID 327273 (2012)

18. Abdeljawad, T, Karapınar, E, Taş, K: Existence and uniqueness of a common fixed point on partial metric spaces. Appl. Math. Lett. 24(11), 1894-1899 (2011)

19. Altun, I, Sola, F, Simsek, H: Generalized contractions on partial metric spaces. Topol. Appl. 157, 2778-2785 (2010)

20. Aydi, H, Abbas, M, Vetro, C: Partial Hausdorff metric and Nadler's fixed point theorem on partial metric spaces. Topol. Appl. 159, 3234-3242 (2012) 
21. Aydi, H, Barakat, MA, Felhi, A, Isik, H: On $\phi$-contraction type couplings in partial metric spaces. J. Math. Anal. 8, 78-89 (2017)

22. Aydi, H, Jellali, M, Karapinar, E: Common fixed points for generalized $\alpha$-implicit contractions in partial metric spaces: consequences and application. RACSAM 109, 367-384 (2015)

23. Aydi, H, Karapinar, E: A Meir-Keeler common type fixed point theorem on partial metric spaces. Fixed Point Theory Appl. 2012, $26(2012)$

24. Aydi, H, Karapinar, E: New Meir-Keeler type tripled fixed point theorems on ordered partial metric spaces. Math. Probl. Eng. 2012, Article ID 409872 (2012)

25. Aydi, H, Amor, SH, Karapinar, E: Berinde type generalized contractions on partial metric spaces. Abstr. Appl. Anal. 2013, Article ID 312479 (2013)

26. Chi, KP, Karapınar, E, Thanh, TD: On the fixed point theorems in generalized weakly contractive mappings on partial metric spaces. Bull. Iran. Math. Soc. 39(2), 369-381 (2013)

27. Ćirić, L, Samet, B, Aydi, H, Vetro, C: Common fixed points of generalized contractions on partial metric spaces and an application. Appl. Math. Comput. 218, 2398-2406 (2011)

28. Karapınar, E: A note on common fixed point theorems in partial metric spaces. Miskolc Math. Notes 12(2), 185-191 (2011)

29. Karapınar, E, Erhan, IM, Ulus, AY: Fixed point theorem for cyclic maps on partial metric spaces. Appl. Math. Inf. Sci. 6, 239-244 (2012)

30. Karapinar, E, Inci, ME: Fixed point theorems for operator on partial metric spaces. Appl. Math. Lett. 24, 1894-1899 (2011)

31. Aydi, H, Karapinar, E, Vetro, C: On Ekeland's variational principle in partial metric spaces. Appl. Math. Inf. Sci. 9, 1-6 (2015)

32. Aydi, H, Karapinar, E, Kumam, P: A note "On modified proof of Caristi's fixed point theorem on partial metric spaces, Journal of Inequalities and Applications 2013, 2013:210". J. Inequal. Appl. 2013, 355 (2013)

33. Samet, B, Vetro, C, Vetro, F: From metric spaces to partial metric spaces. Fixed Point Theory Appl. 2013, 5 (2013)

34. Cho, SH, Bae, JS: Fixed points of weak $\alpha$-contraction type maps. Fixed Point Theory Appl. 2014, 175 (2014)

35. Guo, D, Lakshmikantham, V: Coupled fixed points of nonlinear operators with applications. Nonlinear Anal. 11(5), 623-632 (1987)

36. Berzig, $\mathrm{M}$, Karapinar, E: Fixed point results for $(\alpha \psi, \beta \phi)$-contractive mappings for a generalized altering distance. Fixed Point Theory Appl. 2013, 205 (2013)

37. Cho, SH: Fixed point theorems for rational contraction maps in partial metric spaces with applications. Far East J. Math. Sci. 102(8), 1809-1829 (2017)

\section{Submit your manuscript to a SpringerOpen ${ }^{\odot}$ journal and benefit from:}

- Convenient online submission

- Rigorous peer review

- Open access: articles freely available online

- High visibility within the field

- Retaining the copyright to your article

Submit your next manuscript at $\gg$ springeropen.com 